\title{
Digitalna humanistika: modna muha ali naš (bibliografski) vsakdan?
}

\author{
Digital humanities: a whim or a (bibliographical) routine?
}

\section{Sonja Svoljšak ${ }^{1}$}

IZVLEČEK: Članek predstavlja in analizira izbrane projekte in raziskovalne iniciative s področja digitalne humanistike, v katere so aktivno vključene knjižnice in druge dediščinske ustanove. Ti ambiciozni globalni projekti dopolnjujejo obstoječa znanja o splošnih in specifičnih družbenih in kulturnozgodovinskih fenomenih ter pisni kulturni dediščini z uporabo spletnih aplikacij in orodij ter kolaborativnega, lokacijsko neodvisnega raziskovalnega pristopa. Posredno članek ponuja vpogled $v$ preplet analognosti in digitalnosti na področju digitalne humanistike in v možnosti, ki jih ta ponuja raziskovalcem in knjižnicam kot upravljavkam z metapodatki in digitalnimi objekti - tudi kot potencialnim pobudnikom, gostiteljem in aktivnim partnerjem $v$ projektih in mednarodnih raziskovalnih skupnostih in iniciativah.

KLJUČNE BESEDE: digitalna humanistika, knjižnice, raziskave, projekti

ABSTRACT: The article presents and analyses selected digital humanities projects and research initiatives in which libraries and other heritage institutions participate actively. These ambitious global projects supplement the existing knowledge on general and specific social and cultural-historical phenomena in the field of written cultural heritage with the help of web-based applications, tools and the collaborative location-independent research approach. Indirectly, the article also gives insight into the analogue and the digital aspects of digital humanities, as well as into the opportunities that the field offers to researchers, libraries, and other heritage institutions - also as potential initiators, hosts and active partners in such projects, as well as in in the international research communities and initiatives.

KEYWORDS: digital humanities, libraries, research, projects

\section{Uvod}

V množici virov, ki so dostopni v strokovni literaturi, predvsem pa na spletu, je po mnenju avtorice tega prispevka, eno najkonciznejših definicij digitalne humanistike mogoče najti na domači strani Cambridge Digital Humanities (2020), ki ima kot del Univerze v Cambridgeu eno najdaljših raziskovalnih tradicij na tem področju. Glasi se: „Digitalna humanistika je široko področje raziskav in znanstvenih dejavnosti, ki zajema ne le uporabo digitalnih metod s strani raziskovalcev s področja humanistike in sodelovanje strokovnjakov s področja humanistike z računalniškimi in naravoslovnimi disciplinami, ampak tudi način, kako humanistika ponuja specifičen vpogled $v$ najpomembnejša družbena in kulturna vprašanja, ki jih prinaša razvoj digitalnih tehnologij. Delo na tem področju je nujno kolaborativno, saj vključuje več veščin, disciplin in strokovnih področij«. Temu bi lahko dodali še, da je digitalna humanistika izrazito lokacijsko neodvisna, saj večina dejavnosti in raziskav poteka z uporabo infrastrukture oziroma digitalnih aplikacij in orodij, ki temeljijo na spletnih tehnologijah in rešitvah. Eden obsežnejših

\footnotetext{
${ }^{1}$ Dr. Sonja Svoljšak, bibliotekarska svetnica, Narodna in univerzitetna knjižnica (NUK), Ljubljana, Slovenija,
} sonja.svoljsak@nuk.uni-li.si. 
naborov programske opreme oziroma orodij za različne dejavnosti na področju digitalne humanistike je na voljo na domači strani NYU Libraries (Digital, 2020).

Humanistične in družboslovne znanosti, ki uporabljajo tovrstna delovna in raziskovalna okolja in orodja, so predvsem zgodovinopisje, arheologija, antropologija, etnologija, jezikoslovje, kulturne študije, literarne vede, umetnostna zgodovina, filozofija, teologija, geografija, sociologija, politične vede, pravo, muzikologija, informacijska znanost, bibliotekarstvo, pa tudi različne interdisciplinarne in multidisciplinarne vede.

Med letoma 2016 in 2019 je v okviru Delovne skupine za digitalno humanistiko in digitalno kulturno dediščino LIBER (2020a) potekalo več aktivnosti, katerih cilj je bil ugotoviti, kakšna je vloga knjižnic in drugih dediščinskih ustanov na področju digitalne humanistike, kaj lahko knjižnice (tudi kot upravljavke z metapodatki in digitalnimi objekti) prispevajo k razvoju področja, na kakšne načine se lahko bibliotekarska stroka s svojimi specifičnimi znanji kar najbolj (pro)aktivno vključuje v raziskovalno skupnost "digitalnih humanistov« in kako je mogoče vzpostaviti povratne zanke pri uporabi raziskav v knjižnicah in stroki. Izsledki delovne skupine so bili objavljeni $v$ obliki strnjenih povzetkov, ki vključujejo tudi sezname izbrane oziroma temeljne literature in virov za posamezno temo (LIBER, 2020b). Eden od namenov omenjenih aktivnosti je bil vnesti nekoliko strukture $v$ poplavo (dostikrat fragmentarnih) informacij s področja digitalne humanistike in knjižnic.

Najpomembnejši dejavniki, ki knjižnicam in drugim dediščinskim ustanovam omogočajo vlogo (pro)aktivnih deležnikov na področju digitalne humanistike, so obsežne izkušnje pri upravljanju z objekti kulturne dediščine, (bibliografskimi) metapodatki in digitalnimi objekti ter njihova tradicija zagotavljanja širokega spektra podpore raziskovalcem in raziskovalnim skupnostim. Številne nacionalne in univerzitetne knjižnice so $v$ preteklih letih prek vzpostavljanja tako imenovanih digitalnih laboratorijev in delavnic postale nepogrešljivi partnerji pri razvoju področja, raziskovalcem pa poleg znanj in veščin zagotavljajo tudi prostore in infrastrukturo za delo. Leta 2019 je na temo vzpostavljanja digitalnih laboratorijev $v$ dediščinskih ustanovah na primer izšel obsežnejši priročnik (Mahey, M. et al., 2020). Tudi v Sloveniji deluje skupina DARIAH-SI (2020), ki je del panevropske digitalne raziskovalne infrastrukture za umetnost in humanistiko DARIAH-EU (2020). Njena osnovna dejavnost zajema oblikovanje, implementacijo in promocijo raziskovanja, projektov, orodij in najboljših praks na področju digitalne humanistike. $V$ povezavi z DARIAH-SI, pa tudi neodvisno, potekajo posamezne raziskave in projekti, kot je na primer projekt Neznani rokopisi slovenskega slovstva 17. in 18. stoletja (2011), vendar med aktivnimi partnerskimi ustanovami vsaj trenutno ni nobene knjižnice.

Ne glede na obilico entuziazma, ki spremlja digitalno humanistiko, pa nekateri vidnejši akterji na razmah področja gledajo z določeno mero skepse. A. Degkwitz (2018), ki je bil med drugim tudi podpredsednik delovne skupine LIBER za digitalno humanistiko in digitalno kulturno dediščino, je tako denimo zapisal: "Analogno nas vabi - ali celo sili - k doživljanju in premoru in razmišljanju. V nasprotju z digitalnim analogno ni zgolj kopija ali reprezentacija. Če bi sprejeli digitalno humanistiko in njene posledice kot namen sam po sebi, bi to razblinilo vse izkušnje v korist neskončnih zank nesmiselnega medsebojnega delovanja. To je cena, ki jo plačujemo za digitalne medije. In to je cena, ki je redko vključena v analize stroškov in koristi. Analogno lahko prekine neskončno zanko digitalnega, vendar le, če analogni pojavi ostanejo naš cilj.« Temu razmisleku v prid govori dejstvo, da je kljub številnim potencialom aplikacij in orodij velik del 
digitalne humanistike po svoji naravi v bistvu izrazito analogen, saj večina problemskih izhodišč in raziskovalnih izsledkov še vedno temelji na povsem "analognem« vložku, ki nenazadnje denimo vključuje tudi programiranje oziroma "učenje» programov za besedilno analizo (digitalna lingvistika) in podatkovno rudarjenje. Na obstoječih epistemoloških in metodoloških izhodiščih posameznih znanosti in ved je zasnovana tudi praktično celotna raziskovalna infrastruktura.

\section{Digitalna humanistika in knjižnice}

Knjižnice $s(m) o v$ digitalno humanistiko lahko vpete aktivno, denimo prek sodelovanja $v$ različnih projektih ter kot gostiteljice digitalnih laboratorijev in delavnic, pa tudi pasivno. Metapodatke in digitalne objekte vseh vrst, ki jih prispevamo v različne bibliografske baze in digitalne zbirke, uporabljajo tudi zelo oddaljeni raziskovalci in raziskovalne skupnosti. Lahko jih agregirajo, rudarijo, indeksirajo, mapirajo, povezujejo, analizirajo, rekonstruirajo, vizualizirajo ipd. S tem ti metapodatki dobivajo nove dimenzije in vrednosti, iz njih pa nastajajo tudi povsem novi raziskovalni viri.

Za nazornejšo predstavo o tem, na kakšne načine se bibliografski metapodatki, digitalni objekti ter bibliotekarska in bibliografska strokovna znanja in veščine (lahko) umeščajo v svet digitalne humanistike, bo $v$ nadaljevanju prispevka predstavljenih nekaj najvidnejših mednarodnih projektov oziroma raziskovalnih infrastruktur, $v$ katere so aktivno vključene knjižnice in ki na osnovi kolaborativnega, lokacijsko neodvisnega raziskovalnega pristopa ter spletnih aplikacij in orodij nadgrajujejo obstoječa spoznanja o splošnih in specifičnih družbenih in kulturnozgodovinskih fenomenih $v$ različnih obdobjih ter kulturni dediščini nasploh. Poudarek bo predvsem na tistih projektih, ki se ukvarjajo z analizami, rekonstrukcijami in vizualizacijami razpršenih historičnih korpusov in so pri tem neposredno odvisni od bibliografskih (meta)podatkov ter digitalnih reprodukcij objektov kulturne dediščine, po svoji naravi in z raziskovalnimi funkcionalnostmi pa so mnogo več kot zgolj zbirke metapodatkov in digitalnih objektov, saj omogočajo aktivno in lokacijsko povsem neodvisno sodelovanje. Posreden namen izbranih predstavitev je med drugim vpogled $v$ preplet analognosti in digitalnosti na področju digitalne humanistike in $v$ možnosti, ki jih ta ponuja knjižnicam in raziskovalcem $v$ knjižnicah in drugih dediščinskih ustanovah - tudi kot potencialnim pobudnikom, gostiteljem in aktivnim partnerjem $v$ tovrstnih projektih in raznih raziskovalnih skupnostih.

\section{Fragmentologija in Fragmentarium: raziskovanje fragmentov in rekonstrukcija srednjeveških kodeksov}

Čeprav uradna ocena ne obstaja, je povsem verjetno, da število ohranjenih fragmentov rokopisov iz latinskega (zahodnoevropskega) srednjega veka presega petnajst milijonov. Nekatere težave in ovire, povezane $\mathrm{z}$ njihovim raziskovanjem, $v$ zadnjih letih premošča mednarodni spletni raziskovalni laboratorij Fragmentarium (2020). Zasnovan je kot prosto dostopno, vendar strokovno kurirano raziskovalno omrežje, temelji pa na tehnologijah, ki so bile razvite za potrebe baze E-codices - Virtual Manuscript Library of Switzerland (2020). Knjižnicam, drugim dediščinskim ustanovam, zasebnim zbirateljem in raziskovalcem omogoča objavljanje digitalnih reprodukcij fragmentov, njihovo katalogizacijo oziroma vnos metapodatkov po enotnih standardih, iskanje, primerjalno analizo oziroma vizualno vzporejanje fragmentov iz različnih hranilišč ter njihovo opisovanje in transkripcijo. Na podlagi metapodatkov, digitalnih kopij ter opisov in transkripcij je tako mogoča rekonstrukcija danes 
razpršenih srednjeveških kodeksov ne glede na njihovo trenutno hranilišče ter ne glede na lokacijo ustanov in posameznikov, ki jih raziskujejo. $\mathrm{V}$ okviru Fragmentariuma potekajo tudi usposabljanja in tematske delavnice.

Spletna aplikacija Fragmentarium temelji na IIIF (International, 2020) in programskem jeziku mySQL, združuje pa več orodij: orodje za katalogizacijo oziroma vnos metapodatkov, orodje za upravljanje s spletnimi vsebinami, orodje za vnos kontroliranih označevalcev, ključnih besed in faset, orodje, ki omogoča iskanje in raziskovanje digitalnih reprodukcij in metapodatkov, njihovo primerjavo, navzkrižno primerjavo in (vizualno) vzporejanje, in orodje, ki omogoča povezovanje in združevanje metapodatkov ter digitalnih reprodukcij, s tem pa tudi rekonstrukcijo posameznih kodeksov. Orodja so sicer zasnovana na tradicionalnih raziskovalnih pristopih in metodah. Močan poudarek je na vizualno in besedilno primerjalni analitiki; omogočajo jo standardizirani bibliografski metapodatki, po katerih je mogoče iskati in brskati, v kombinaciji s pripadajočimi digitalnimi reprodukcijami fragmentov (slika 1). Kombinacija strokovnega znanja in tehničnih možnosti, ki jih ponujajo orodja, pravzaprav omogoča uresničitev projektov in iniciativ posameznih raziskovalcev in raziskovalnih skupin za dopolnitev obstoječih spoznanj o vsebinskih ter umetnostnih in drugih vidikih membra disiecta srednjeveških kodeksov na enem mestu. Ti podatki in iz njih izhajajoča spoznanja vodijo $\mathrm{k}$ celostnejšemu poznavanju in razumevanju srednjeveške kulture, znanosti in umetnosti, kot se odražajo prek pisne dediščine. S stališča knjižnic, ki hranijo največ fragmentov in ki tudi prevladujejo med projektnimi partnerji, je Fragmentarium zanimiv s številnih vidikov; na prvem mestu je gotovo dejstvo, da je to trenutno največja tovrstna zbirka podatkov, ki temelji na enotnih metapodatkovnih standardih.

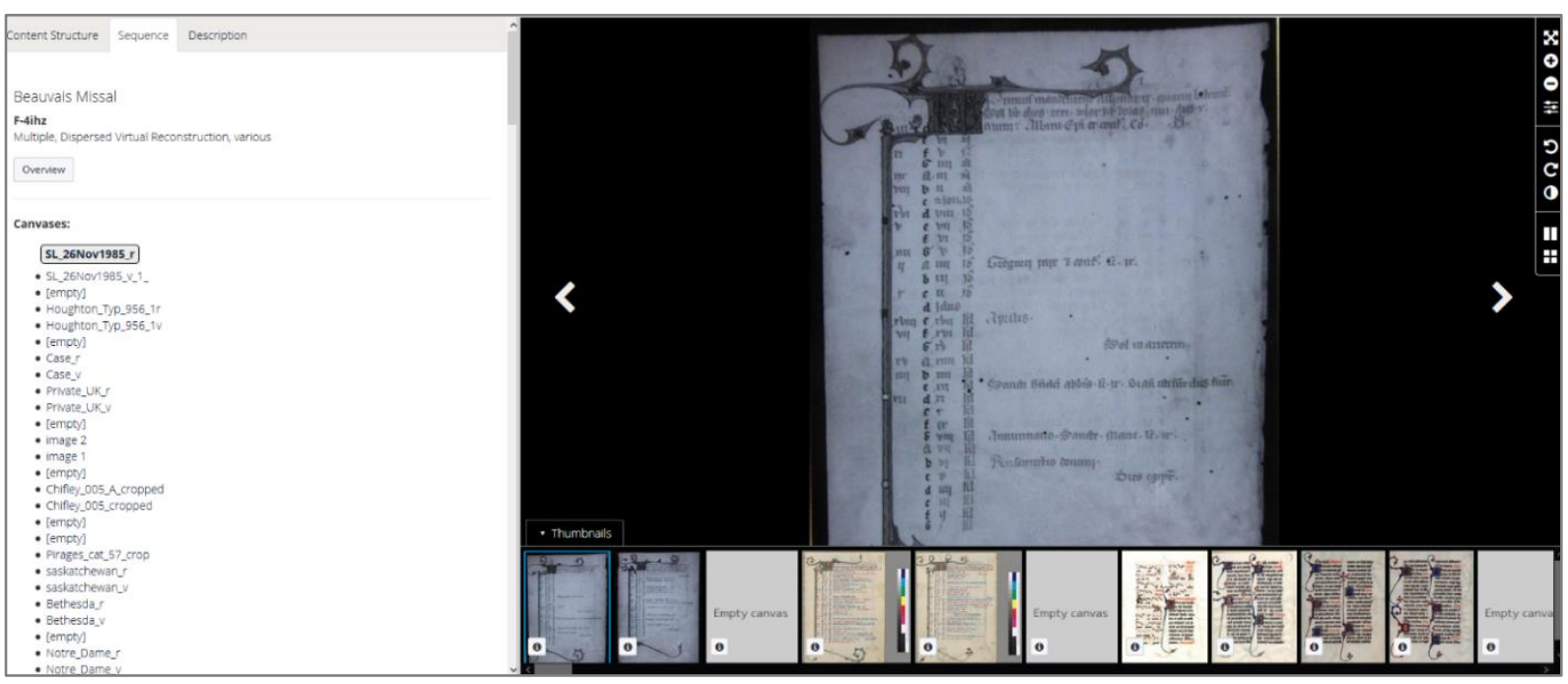

Slika 1: Misal iz Beauvaisa, ki je bil (deloma) rekonstruiran na podlagi metapodatkov in digitalnih kopij fragmentov iz več kot 50 različnih javnih ustanov in zasebnih zbirk (Vir: Fragmentarium, https://fragmentarium.ms/searchresult/overview/F-4ihz, 2020) 


\section{Material Evidence in Incunabula (MEI): globalna bibliografska baza in analitično orodje za področje založništva, knjigotrštva, knjižne umetnosti ter vsebinske strukture in recepcije prvotiskov}

Ocenjeno je, da je na svetu ohranjenih približno 30.000 izdaj prvotiskov v približno 450.000 izvodih. Ti kot celota predstavljajo specifičen korpus, ki priča o različnih vidikih knjižne kulture $\checkmark$ najzgodnejšem obdobju tiskarstva. Podatki, ki se nanašajo na posebnosti posameznih izvodov prvotiskov, so sicer (pretežno $v$ opisni obliki) že prisotni $v$ knjižničnih katalogih. Digitalna humanistika knjižnicam omogoča, da strokovno podprejo raziskovalno skupnost, zastavlja pa se še vrsta vprašanj o drugih potencialih in vlogi knjižnic na tem področju. Precej večjih zbirk je že na voljo tudi v digitalni obliki, vendar pa posamezni izvodi ali posamezne zbirke metapodatkov in digitalne zbirke prvotiskov ne morejo ponuditi zanesljivih odgovorov na širša vprašanja, kot so na primer:

- Katere knjige so bile tiskane $v$ Benetkah in so bile $v$ 15. stoletju kupljene in uporabljane v Nemčiji ali na Poljskem? Kdo jih je uporabljal in kako? So jih brale tudi ženske?

- Kakšne knjige so $v$ 15. stoletju $v$ Italiji in Franciji kupovali študentje, pravniki ali duhovniki?

- Katere izdaje matematičnih del so kupovale verske ustanove?

- Kdo je v renesansi kupoval Ptolemejeve Kozmografije? Kdo jih je zbiral v 18. stoletju?

- Ali lahko določimo število tiskanih knjig iz 15 . stoletja, ki so prišle $v$ evropske in ameriške zbirke kot neposredna posledica razpusta verskih institucij in njihovih knjižnic v 18. in 19. stoletju?

- Kolikokrat so bila v 15. stoletju natisnjena dela Petrarce ali Boccaccia?

- Kolikšen je bil delež klasičnih, srednjeveških ali sodobnih besedil, objavljenih v prvih petdesetih letih tiskarstva?

- Katera dela, natisnjena v 15. stoletju, so danes ohranjena v največjem številu izvodov? In katera $v$ najmanjšem? Kdo je izbiral, urejal in prispeval besedila v izdajah iz 15. stoletja? Koliko del je bilo v 15. stoletju natisnjenih v eni, koliko pa v več izdajah? Koliko izdaj vsebuje ilustracije?

- Ali lahko danes ocenimo kakovost in število tiskov iz 15. stoletja, ki smo jih izgubili v 500-letnem obdobju?

Da bi lahko odgovorili na ta in na druga vprašanja, povezana z založništvom, knjigotrštvom, knjižno umetnostjo, knjižno kulturo ter vsebinsko strukturo in recepcijo posameznih izdaj in izvodov prvotiskov, s tem pa tudi vseh ohranjenih prvotiskov kot specifičnega historičnega korpusa, je bila leta 2016 v okviru projekta 15cBooktrade (2020) zasnovana podatkovna baza MEI - Material Evidence in Incunabula (2020). Namenjena je beleženju in iskanju podatkov o značilnostih in zgodovini posameznih izvodov danes ohranjenih prvotiskov, saj le-ti (predvsem s svojo sekundarno vsebino in formo) lahko ponudijo natančnejši vpogled v zgoraj omenjene fenomene na globalni ravni. Standardizirani metapodatki v bazi, ki se nanašajo na posamezno izdajo, izhajajo iz baze ISTC (Incunabula, 2016), metapodatke, ki se nanašajo na posebnosti posameznih izvodov, pa je treba ročno vnesti v obrazec. Vnos (možna je izbira s spustnih seznamov ali vnos besedila) vključuje podatke o vezavi izvoda, vodnih znakih, rokopisnih dodatkih, znamenjih nekdanjega lastništva in kronologiji nekdanjih lastnikov (provenience), ceni, trenutnem hranilišču in nekatere druge podatke, ki so značilni za vsak posamezni izvod. Vsakemu opisovanemu izvodu oziroma zapisu je po končani avtopsiji in opisu dodeljen 
edinstven identifikator, lokacije provenienc so povezane tudi z bazo podatkov Geographic Regions, s čimer je omogočena vizualizacija kroženja prvotiskov skozi stoletja, od kraja izdelave pa vse do njihovih sedanjih lokacij. MEI dopolnjujejo naslednje tri pridružene oziroma povezane baze: baza nekdanjih lastnikov, baza parabesedil in baza ilustracij, ki je namenjena iskanju in primerjavi likovnih elementov oziroma ilustracij v okviru istega izvoda, v okviru iste izdaje določenega dela, $v$ okviru različnih izdaj določenega dela in $v$ okviru različnih izdaj različnih del (15cBooktrade, 2020).

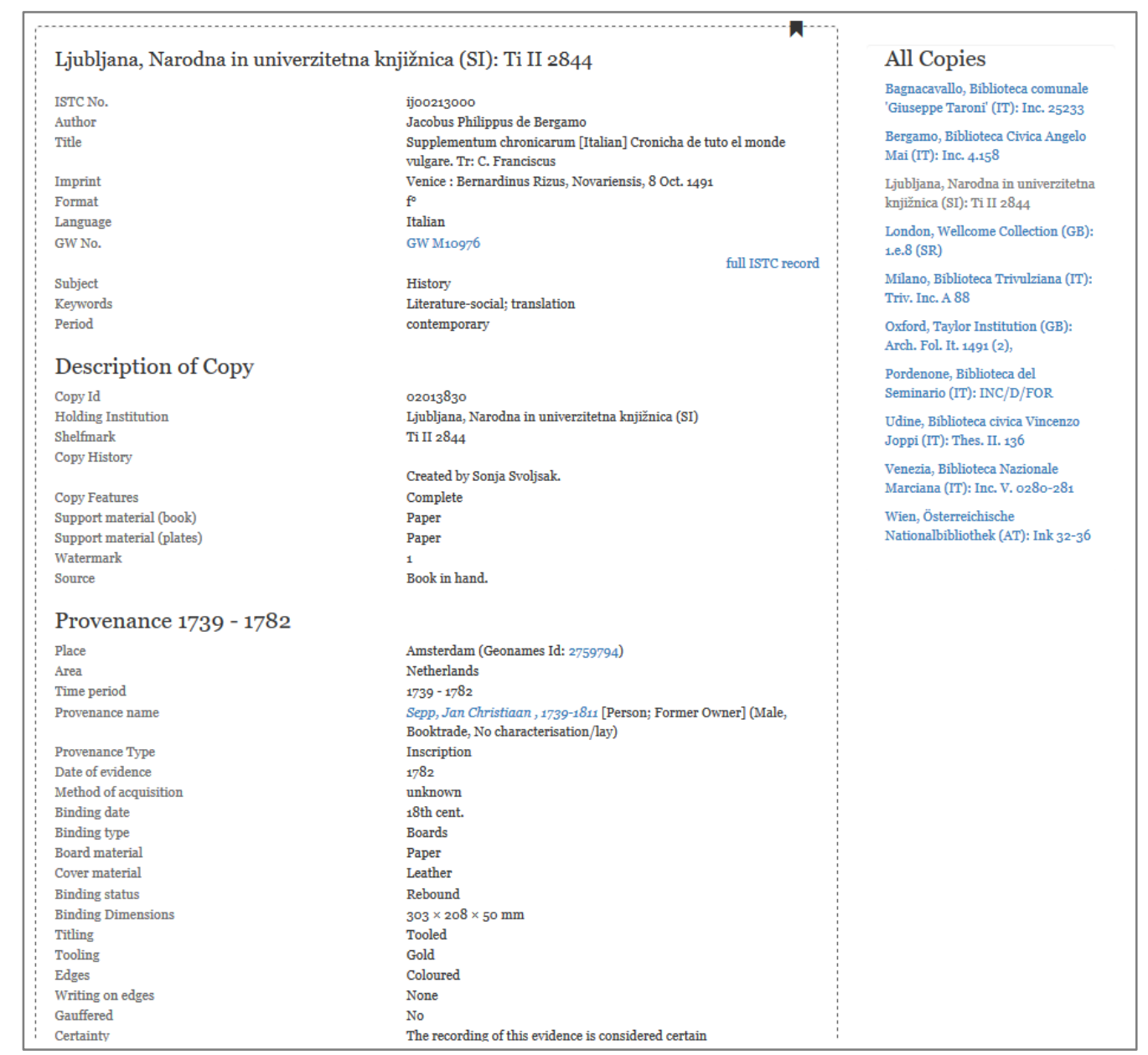

Slika 2: Del zapisa za izvod Supplementum chronicarum Jakoba Filipa iz Bergama iz Zbirke Žige Zoisa, ki ga hrani NUK (Vir: MEI, https://data.cerl.org/mei/02013830, 2020)

Pri dopolnjevanju baze, ki se je leta 2014 pod vodstvom Cristine Dondi s fakultete Lincoln College Univerze v Oxfordu in Data Conversion Group z Univerze v Göttingenu začela kot evropski projekt, od leta 2019 dalje pa poteka pod okriljem CERL (Consortium, 2020), sodeluje svetovna raziskovalna skupnost na čelu z raziskovalci - bibliografi iz nacionalnih in univerzitetnih knjižnic, ki hranijo večje zbirke prvotiskov. Problematiko manjših in nejavnih zbirk na primer $v$ Italiji rešujejo tudi ob pomoči potujočih katalogizatorjev/popisovalcev, ki obiskujejo samostane, razne zasebne ustanove in zbiratelje. Vsako leto je za namen dopolnjevanja baze razpisanih tudi več raziskovalnih štipendij. Za pristop $\mathrm{k}$ sodelovanju je potrebna predhodna udeležba na delavnici, $\vee$ času nastanka tega prispevka pa je bilo $v$ MEI popisanih 51.681 posameznih izvodov prvotiskov s celega sveta, predvsem pa iz evropskih in ameriških zbirk. Čeprav se opisom posameznih izvodov pogosto pridružujejo tudi digitalne 
kopije, je ročen vnos (meta)podatkov, ki so na podlagi avtopsije specifični za posamezen izvod, bistvenega pomena za analize, ki jih MEI predvideva oziroma omogoča (slika 2).

\section{Mapping the Republic of Letters: analiza in vizualizacija korespondenčnih in drugih medosebnih stikov od renesanse do razsvetljenstva}

Mapping the Republic of Letters (2020) je projekt skupine Humanities+Design in Univerze Stanford, med partnerskimi ustanovami pa so tudi posamezne evropske univerze in raziskovalne ustanove. Osredotoča se na raziskovanje omrežij, ki so jih prek literarne republike, osebnih stikov, objav in potovanj ustvarili posamezni znanstveniki in literati od renesanse do razsvetljenstva. Ta omrežja so bila od 16. do 19. stoletja ključna za diseminacijo znanstvenih in drugih informacij, s tem pa tudi za razvoj znanosti, književnosti, ekonomije, kulture, politike in drugih področij družbe. Namen posameznih študij primerov, med katerimi so denimo Condorcetova, D'Alembertova, Voltairova, Franklinova, Galilejeva, Lockova in Kircherjeva korespondenca, vizualne in relacijske rekonstrukcije evropskih plemiških zrelostnih potovanj (angl. grand tours), literarnih salonov, znanstvenega korespondenčnega omrežja v okviru Španskega imperija in krajev, v katerih so bila izdana Voltairova dela, je ugotoviti, kako obsežne so bile te mreže, kakšne so bile njihove značilnosti in kako so se razvijale.

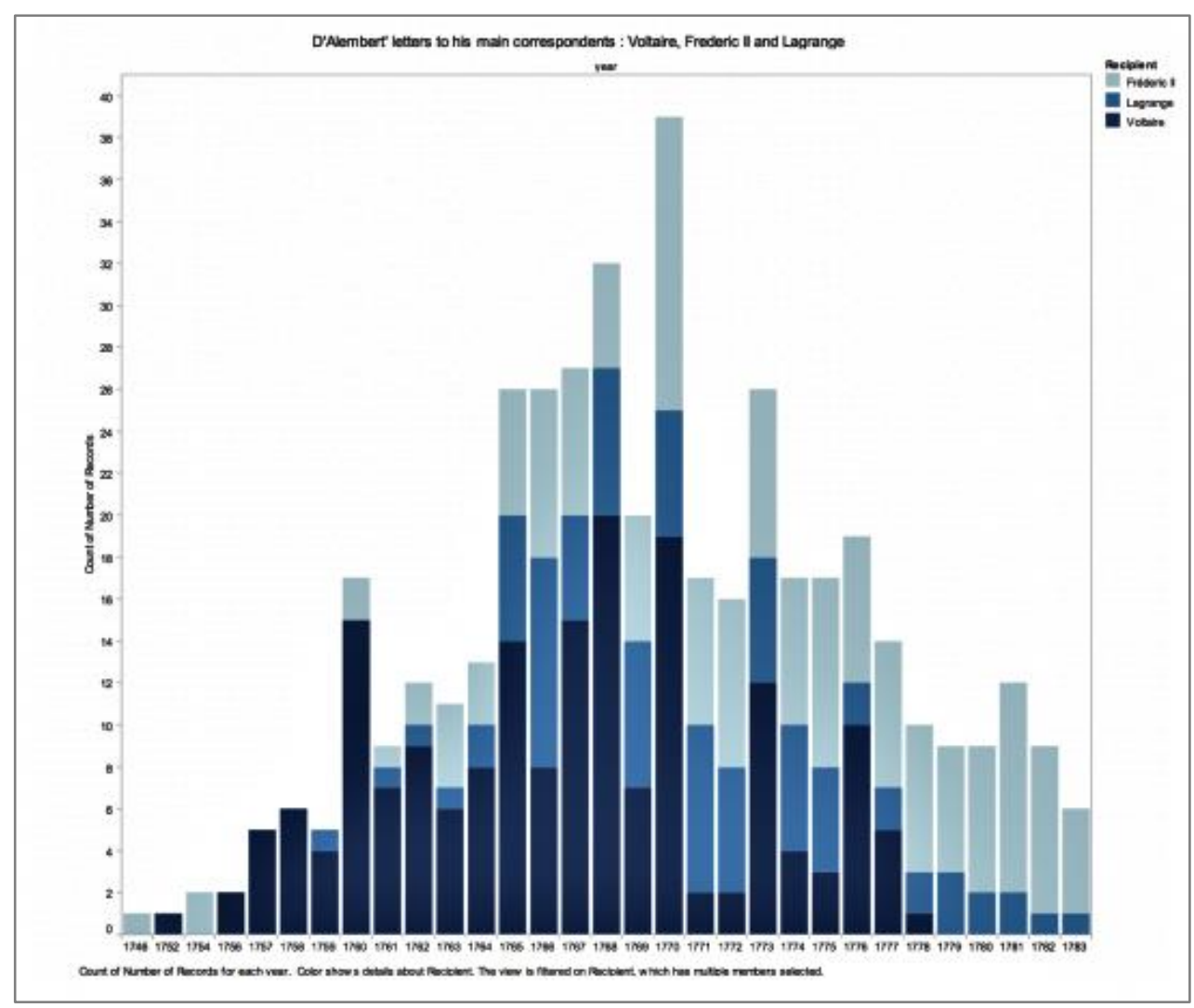

Slika 3: Grafični prikaz D'Alembertove korespondence z Voltairom, Lagrangeem in Friderikom II. med letoma 1748 in 1873 (Vir: Mapping the Republic of Letters, http://republicofletters.stanford.edu/casestudies/dalembert.html, 2020)

Mrežo stikov med posamezniki pa tudi ustanovami, kakršne so bile recimo znanstvene akademije, je mogoče rekonstruirati na podlagi posameznih študij in baz (meta)podatkov, 
digitalnih zbirk ohranjenih pisem in drugih zapiskov ter objavljenih del, ki jih hranijo različne dediščinske ustanove na čelu s knjižnicami. Podatki o osebnih in drugih stikih posameznih oseb, zbranih z uporabo aplikacij in orodij za vizualizacijo različnih družbenih fenomenov, omogočajo tudi njihove statistične, kronološke in prostorske analize ter prikaze (sliki 3 in 4).

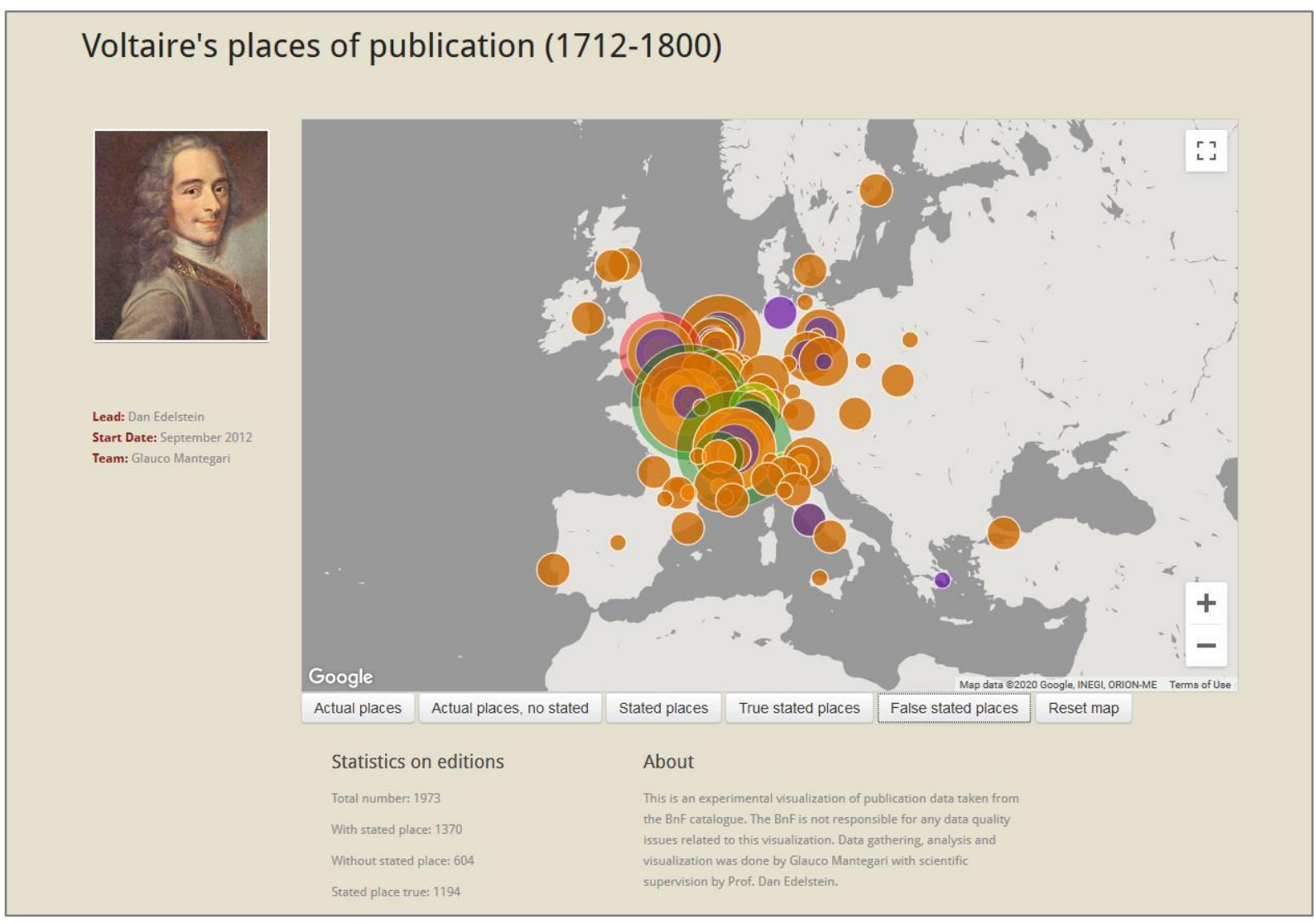

Slika 4: Vizualizacija krajev izida Voltairovih del, ki jih hrani Francoska nacionalna knjižnica, v obdobju med 1712 in 1800 s filtri za: dejanske kraje izida, kraje izida, ki niso navedeni, pa so bili ugotovljeni iz drugih virov, kraje izida, ki so navedeni, kraje izida, ki so navedeni in so tudi dejanski kraji izida, ter namenoma napačno navedene kraje izida (Vir: Mapping the Republic of Letters, http://republicofletters.stanford.edu/casestudies/voltairepub.html, 2020)

\section{Nekaj sklepnih misli}

Digitalna humanistika knjižnicam omogoča, da strokovno podprejo raziskovalno skupnost, zastavlja pa se še vrsta vprašanj o drugih potencialih in vlogi knjižnic na tem področju. Prvo je gotovo vprašanje o strategiji upravljanja z metapodatki ter gradnji bibliografskih baz in digitalnih zbirk na tak način, da bi bile te uporabne za čim več raziskovalnih področij, vključno z lokacijsko neodvisno in avtomatizirano analitiko večjih količin (meta)podatkov in digitalnih objektov. Bolj(e) kot so ti strukturirani, medsebojno povezani in kontekstualizirani, bolj(e) se lahko posvečamo vsebinskim vidikom bibliografskega in drugega strokovnega dela, raziskovanju in razvoju, spoznavanju in uporabi sodobnih standardov, metodologij in (digitalnih) orodij ter (kritičnemu) razumevanju svojega strokovnega dela $v$ širšem znanstvenoraziskovalnem kontekstu. Drugo je pogosto prezrto vprašanje lastnih iniciativ knjižnic na področju sistematičnega raziskovanja in kontekstualizacije večjih, predvsem globalno relevantnih korpusov pisne kulturne dediščine tudi v digitalnem okolju oziroma z 
uporabo (kolaborativno zasnovanih) spletnih aplikacij in analitičnih orodij. Le z lastnimi pobudami in (pro)aktivnim pristopom lahko knjižnice in druge ustanove, ki hranijo kulturno dediščino, postanejo aktivni deležniki in sodelavci v projektih, tudi tistih, ki po svoji naravi in zasnovi deloma ali v celoti spadajo na področje digitalne humanistike. Potenciali bibliografskih baz in digitalnih zbirk so - v kombinaciji s premišljenimi vprašanji, ki si jih zastavimo v zvezi z njihovo naravo, vlogo, pomenom in kar najširšo možno uporabnostjo - praktično neomejeni. Kljub temu pa se, kot pravi A. Degkwitz (2018) in kot je razvidno tudi iz izbranih projektov in iniciativ, predstavljenih $v$ tem članku, digitalna humanistika začne $s$ temeljitim poznavanjem ter strokovno bibliografsko obravnavo primarnih virov in korpusov, ki jih hranimo. Aplikacije in orodja, ki spadajo v območje »digitalnega«, so pri tem pravzaprav večinoma le premišljeno zasnovani pripomočki za hitrejšo in učinkovitejšo analizo in predstavitev velikih količin pogosto zelo razpršenih podatkov, ki presegajo človeške, torej »analogne« kapacitete.

\section{Reference}

15cBooktrade, 2020. Dostopno na: http://15cbooktrade.ox.ac.uk [25. 5. 2020].

Cambridge Digital Humanities, 2020. Dostopno na: http://www.cdh.cam.ac.uk/cdh/what-isdh [25. 5. 2020].

Consortium of European Research Libraries, 2020. Dostopno na: http://www.cerl.org [25. 5. 2020].

DARIAH-SI, 2020. Dostopno na: http://www.dariah.si [25. 5. 2020].

DARIAH-EU. Dostopno na: http://www.dariah.eu [25. 5. 2020].

Degkwitz, A., 2018. The revenge of the analogue. De Gruyter Conversations, 22. 8. 2018. Dostopno na: https://blog.degruyter.com/the-revenge-of-the-analogue [25. 5. 2020].

Digital humanities: tools \& software: an introductory guide to the wide world of the digital humanities, 15. 4. 2020. Dostopno na: http://guides.nyu.edu/dighum/tools [25. 5. 2020].

E-codices - Virtual Manuscript Library of Switzerland, 2020. Dostopno na: http://www.ecodices.unifr.ch/en [25. 5. 2020].

Fragmentarium: Digital Research Laboratory for Medieval Manuscript Fragments, 2020. Dostopno na: http://fragmentarium.ms/ [25. 5. 2020].

International Image Interoperability Framework (IIIF), 2020. Dostopno na: $\underline{\text { http://iiif.io }}$ [25. 5. 2020].

Incunabula Short Title Catalogue (ISTC), 2016. Dostopno na: http://data.cerl.org/istc [25. 5. 2020].

LIBER. Digital Humanities \& Digital Cultural Heritage Working Group, 2020a. Dostopno na: http://libereurope.eu/strategy/digital-skills-services/digitalhumanities [25. 5. 2020].

LIBER. A Digital Humanities Reading List: Part 1, 2020b. Dostopno na: http://libereurope.eu/blog/2018/01/29/digital-humanities-reading-list-part-1 [25. 5. 2020]. 
Mahey, M., Al-Abdulla, A., Ames, S., Bray, P., Candela, G., Chambers, S., et al., 2020. Open a GLAM Lab. Doha: Digital Cultural Heritage Innovation Labs, Book Sprint. Dostopno na:

http://glamlabs.io/books/open-a-glam-lab [25. 5. 2020].

Mapping the Republic of Letters, 2020. Dostopno na: http://republicofletters.stanford.edu [25. 5. 2020].

Material Evidence in Incunabula (MEI), 2020. Dostopno na: http://data.cerl.org/mei [25. 5. 2020].

Neznani rokopisi slovenskega slovstva 17. in 18. stoletja (NRSS), 2011. Dostopno na: http://ezb.ijs.si/fedora/get/nrss:nrss/VIEW/ [25. 5. 2020]. 